\title{
International smart cities ratings and Russian cities IQ rating comparative study
}

\author{
Sergei Kamolov ${ }^{1, *}$ and Ksenia Kornaukhova ${ }^{1}$ \\ ${ }^{1}$ Moscow State Institute of International Relations (MGIMO University), School of Governance and \\ Politics, Vernadskogo Avenue, 76, Moscow, 119454, Russia
}

\begin{abstract}
.
Research background: The global rating methods of smart cities rankings used in such international organizations as The Intelligent Community Forum, Center for Globalization and Strategy IESE and the United Nations Economic Commission for Europe. International ratings are considered to be a source of information that allows everyone to see and evaluate the scale of it. Along with this phenomenon, the Russian Federation develops national smart cities IQ index which creates the case in rating methodology to help researches assess and better understand smart cities revolution.

Purpose of the article: Major international rankings of smart cities arise alongside one national rating through the prism of the following methodological objects: comparison criteria, scope and structure of the study, research goals and priorities, obtaining information methods, number of criteria, range of estimated values, frequency of ranking compilation and compilers. All mentioned comes up with the basics of global metarating and possibility of its creation.

Methods: As for the main research methods, we turned to analysis and developed our own criteria in comparison, synthesis of metarating and approaches to the study of smart cities development.

Findings \& Value added: As a result of the study, the main criteria of the considered rating assessment methods and the basis of metarating were identified. Based on the study, substantiated conclusions are formulated, and scientifically based recommendations are given to provide the basis for further metarating creation and elaboration.
\end{abstract}

Keywords: smart city; rating; metarating; smart city assessment criteria; strategic planning

JEL Classification: $C 18$; O30; $O 35$

\footnotetext{
* Corresponding author: s.kamolov@inno.mgimo.com
} 


\section{Introduction}

In the context of the formation of an innovative economy and the technological landscape of the modern world order, which are based on the principles of 4.0 industry, there is an inevitable change of emphasis and paradigms associated with the need for further development of models for organizing urban economy and managing the life processes of cities in the near future. In this regard, approaches related to the results of scientific and technical achievements of recent decades are becoming promising areas for building a modern society. In particular, solutions in the field of implementing the concept of smart cities are becoming highly relevant. These trends take on a much more relevant context in connection with the processes of globalization that serves as a prerequisite for an active exchange of experience in the field of rating smart cities.

The relevance of the article is driven by the need of studying the strengths and weaknesses of the methodology of Russian rating of the IQ cities and identifying differences in approaches of local methods from the methods of smart cities rating used in the practice of other international organizations.

The problems under consideration are caused by trends in the development of the theoretical and regulatory framework for implementing the concept of smart cities, which are accompanied by the lack of the necessary mechanism for interaction between responsibility centers at the level of city administrations of Russian regions, that leads to a low degree of practical implementation of the concepts under study.

The purpose of the article is to compare the methods, objects and research criteria used in the framework of the IQ rating and compare this domestic methodology proposed by the Ministry of Construction of the Russian Federation in collaboration with Lomonosov Moscow State University with the methods of rating used by foreign international organizations.

The study hypothesized that there are generally applicable criteria and indicators that represent the core, as well as variable and adaptive indicators used in the methods of rating smart cities used by international organizations and Lomonosov Moscow State University.

The article uses normative sources, including the international standards for rating smart cities ISO/IEC 30146 and ISO/CD 37122, as well as the results of IQ rating proposed by the Ministry of Construction of the Russian Federation. The paper uses the provisions of the concept of smart cities development by E. Towsend, as well as the results of research by such authors as F.Bonomi, R. Milito, S. Addepaolli, L. Vangelista, H. Horabi, S. Walker, T. A. Pardo, and other scientists who have devoted their scientific publications to the problems and prospects of smart cities development. A significant contribution to the development of the theoretical base of the study was made by Russian scientists V. N. Tyushnyakov, A. E. Sahak and E. V. Pakhomov, as well as by other researchers.

The scientific significance of the article is due to the fact that the conclusions obtained as a result of the study provide an opportunity to identify existing shortcomings and contribute to the further development of the concept of smart cities in the Russian Federation. Scientifically the preparation of maturating smart cities, therefore, has importance from the point of view of development of already existing methodological tools, and application of each of the studied methods of rating the realities of separately reporting countries and cities [1].

The outcomes of the article are the results of a study of the features of smart cities rating in the Russian Federation and the possibilities of developing methodology for smart cities rating based on foreign experience in order to improve public administration. The comparative study, which will form the basis for metarating, will improve the tools of public administration and provide opportunities for interaction between Russia and other countries 
in the field of studying and developing the international space of smart cities.

\section{Methodology and Data}

Within the framework of a comparative study of the methodology for smart cities rating, special attention should be paid to the study of methods used by international organizations, which should include the following organizations:

- Intelligent Community Forum (ICF);

- Center for Globalization and Strategy (IESE);

- United Nations Economic Commission for Europe (UNECE).

The approaches proposed by these organizations deserve a detailed study, in which the main role is played by goal setting and reaching the target audience when compiling smart city ratings:

1. The Intelligent Community Forum (ICF) is a non-profit organization that has been evaluating and rating Intelligent Communities every year since 2002.

The method used in the rating assessment is based on a survey and comparison of the resulting data with the global data of ICF. In the process of rating of the cities (communities), six main criteria are used:

- availability of broadband Internet and a developed digital infrastructure - this condition is necessary for the implementation of the following criteria;

- development of labor resources for a knowledge-based economy as a prerequisite for the introduction of innovations based on scientific, intellectual and creative achievements, with the mandatory availability of information exchange opportunities and broad access to scientific knowledge;

- development of innovative economy and management - the use of innovations is one of the criteria for the successful implementation of smart city concepts and includes the development of digital, information and communication technologies, as well as the widespread usage of artificial intelligence and robotics in municipal economy and urban management;

- involvement of citizens in the processes of economic transformation is a consequence of the processes of democratization and liberalization of countries and communities;

- ensuring equal and free access to digital technologies to overcome social and economic barriers is one of the key criteria that combines indicators that characterize the level of development of digital, information and communication technologies as a factor of access to knowledge and information sources;

- sustainable quality of life, sustainability of economic growth and development - this criterion is based on indicators of economic efficiency, quality of life assessment, and management effectiveness [2].

The research within these criteria and the subsequent rating of smart cities involves the use of 32 indicators, among which there are indicators obtained in the process of filling out tests and answering various questions proposed in the questionnaire (from 3 to 10 questions). Results include a detailed and objective assessment of the smart community based on international standards; an identification of the most promising areas for business and development in terms of market development and the most profitable ones; a guide for appropriate models and strategies for the development of smart community, taking into account all factors of influence.

The key criteria for determining the rating of cities comprise an application of developed models of economic and social transformations of the economy and society; use of advanced technologies and introduction of innovations in economy and spread to nearby regions, including rural areas [3]. 
ICF uses a rigorous analytical method to select the best smart cities. Community representatives fill out a detailed questionnaire based on quantitative and qualitative characteristics used by ICF analysts to calculate and justify the rating, which results in a list of the Top 7 best smart cities in the world. Among the leading positions are Chiayi City, Taiwan Tainan; New Taipei; Ipswich and the Sunshine Coast (Queensland, Australia); Surrey (British Columbia, Canada) and Winnipeg (Manitoba, Canada). Along with compiling the Top 7 of smart community ratings, ICF uses the Smart21 rating, which is based on the rating of 21 smart cities. In general, it sets the future and helps to find new ways to sustainable prosperity for citizens, businesses, and the community as a whole.

2. The IESE Center for Globalization and Strategy conducts research on the processes, patterns and consequences of globalization for the development of entrepreneurship and society in different countries.

The main methodological features of rating assessment:

1) the rating is based on 9 criteria: economy, human capital, social equality, ecology and environmental protection, administrative management, urban planning and architecture, international travel, technology development, mobility and transport;

2) coverage of a large number of cities (174 cities, including 79 capitals, when compiling the index of cities in development in 2019);

3) number of indexes used - 96;

4) wide gradation of the scale used and five levels of ratings [4].

As a result of the rating, cities are grouped according to the indicators measured by the value of the synthetic indicator. Cities are rated as follows: high $(\mathrm{H})$ if they have an index more than 90; relatively high ( $\mathrm{RH})$ if the city is between 60 and 90; medium (M) if it is between 45 and 60; low (L) if it is between 45 and 15; and very low (VL) if it is below 15.

The main difference in the approach to the smart cities rating of the Center for Globalization and Strategy (IESE) is the study of large cities and capitals of economically and industrially developed countries. The top three cities are London, New York and Paris. Occasionally, Seoul (2015) and Amsterdam (2019) occupy the leading positions. Among the Russian cities in the 2019 ranking are Moscow (86th place), Saint Petersburg (121st place) and Novosibirsk (156th place). At the same time, Moscow took the 7th position in the Top 10 cities with the largest human capital (behind Paris and ahead of Washington).

3. United Nations Economic Commission for Europe (UNECE) - regional organization of the United Nations Economic and Social Council (ECOSOC). This international organization promotes the development of economic cooperation between the member countries of the Commission. It is one of the five regional commissions of the United Nations Economic and Social Development Organization (ECOSOC). In addition to European countries, the organization includes the United States, Canada, Israel, Turkey, and Central Asian countries [5].

Methodology used in the preparation of smart city ratings by the United Nations Economic Commission for Europe (UNECE) includes three main groups of indicators:

1) Economy. This group includes 10 criteria and 26 indicators;

2) Environment. This group includes 6 criteria and indicators;

3) Society and culture. This group includes 8 criteria and 27 indicators [6].

The main feature of the rating methodology used by the UNECE is that 72 indicators are evaluated, structured in three areas corresponding to three levels of sustainability. The indicators form 6,8 , and 10 thematic groups that describe areas of priority development of smart cities. The methodology provides basic and additional indicators [7].

Thus, based on the results of the study, it can be concluded that the key priorities of the UNECE rating are ecology and environmental protection, development of Internet Commerce, economic activity of the population, non-discrimination on the basis of gender and security. It should be noted that the priority of the well-being of people, society and 
nature is most obvious in the process of rating the UNECE, while the factors of technology development and innovation do not appear as criteria of primary importance. This is the main difference between the UNECE approach and the rating methods used by ICF and IESE. In addition, it is important to note that the study covers both large cities and developed industrial and commercial and financial centers of Europe.

In 2018, a project called "IQ of cities" was created and tested in the Russian Federation. Its goal is to assess the level of digitalization of urban infrastructure and urban economy. The project developers are the Ministry of Construction of Russia together with Lomonosov Moscow State University. As a result of testing at the end of 2018, the digital technologies of 191 cities of the Russian Federation were evaluated using the "IQ of cities" methodology.

The index was developed as a part of the departmental project "Smart city", implemented as one of the stages in the national projects "Housing and urban environment" and "Digital economy". The main purpose of the "IQ of cities" application is a comprehensive study of the basic level of digital development of modern urban economy and assessment of the level of efficiency of management decisions introduced by cities in the implementation of "Smart city" project. The "IQ of cities" method was tested in the study of cities with a population of more than 100 thousand people [8].

The application of the "IQ of cities" methodology involves the use of a number of criteria and indicators for evaluating the IQ of cities participating in the study, according to 10 groups of criteria: city management; smart housing and utilities; innovations for the urban environment smart housing and utilities; smart urban transport; intelligent public safety systems; intelligent environmental safety systems; tourism and service; intelligent social service systems; economic condition and investment climate; communication network infrastructure.

The research objects include administrative regional centers that are already participating in the "Smart city" project. In addition, the assessment of digitalization of urban management was also applied to pilot cities, whose population does not exceed 100 thousand people, and which also participate in the IQ program.

Overall, the results of applying the methodology of "IQ of cities" by the Ministry of the Russian Federation on the results of the evaluation in 2018, lead to the conclusion according to which the proportion of the population involved in the projects implementing the concept of smart cities is minor, the coverage of cities on the degree of concentration of industrial production and GDP is also quite low, while the level of implementation of the concept of smart cities in some cities can be characterized as fairly high and acceptable [9].

\section{Results}

The performed comparative analysis of smart city ratings was based on seven features used as comparison criteria. The main parameters and characteristics of rating methods for international organizations and the "IQ of cities" methodology by the Ministry of Construction of the Russian Federation are given in Table 1.

The "IQ of cities" methodology is comparable to each of the considered rating methods used by foreign international organizations to study the implementation of the smart cities concept. However, the following differences should be noted:

1) the "IQ of cities" methodology was developed by a state institution and when using it, access to all sources of data and information is open;

2) the application of the "IQ of cities" methodology is limited to the geographical borders of the Russian Federation;

3) the use of the "IQ of cities" methodology has limitations due to technical capabilities, which, in turn, are related to the level of development of telecommunications and digital technologies in the Russian Federation, which makes it difficult to analyze the latest world 
achievements in these areas (for example, the lack of $5 \mathrm{G}$ technologies);

4) the "IQ of cities" method is used in the absence of exchange of experience and information with foreign companies and organizations;

5) a low level of transparency in research, which makes it difficult for independent experts to conduct a rating assessment using the "IQ of cities".

General features and characteristics:

1) using data sets as the basis for rating evaluation;

2) the overall priority of research of foreign ratings (ICF, IESE and UNECE) is to analyze economic indicators and evaluate the use of innovations in urban development;

3 ) the scale of ratings conducted by international organizations ICF and IESE is global

and covers most countries and continents [10].

The differences between methods of rating assessments:

1) focusing on different sources of information-gathering, which determines the differences in the sample structure:

- survey of experts in the field of urban planning and management (IESE);

- survey-interviews of municipal employees and urban population (ICF and UNECE); 


\begin{tabular}{|c|c|c|c|c|c|c|c|}
\hline$\checkmark$ & $a$ & ur & $\Delta$ & $\omega$ & $N$ & - & \# \\
\hline $\begin{array}{l}\oint \\
\frac{8}{0} \\
\frac{9}{9} \\
\frac{9}{5}\end{array}$ & 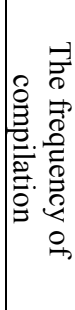 & 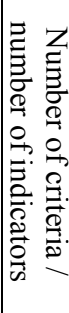 & 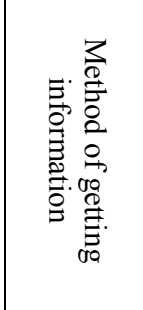 & 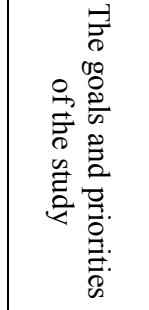 & 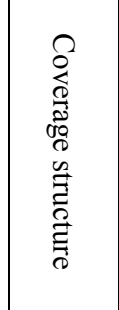 & 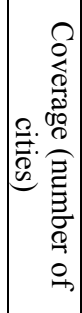 & 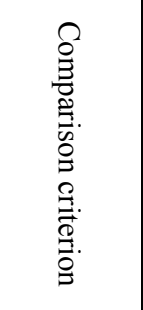 \\
\hline 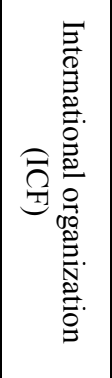 & 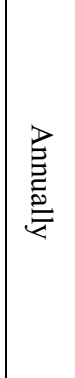 & $\frac{a}{u}$ & 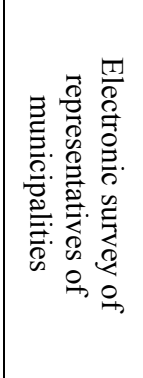 & 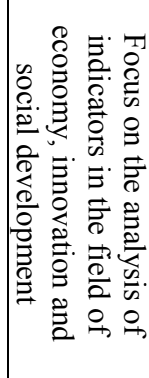 & 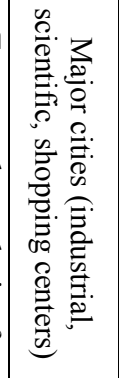 & 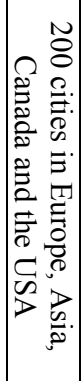 & 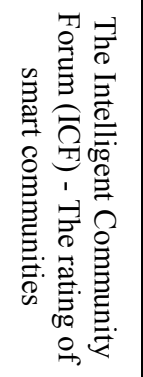 \\
\hline 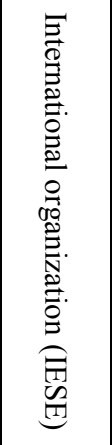 & 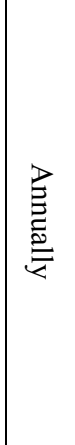 & $\begin{array}{l}0 \\
=\end{array}$ & 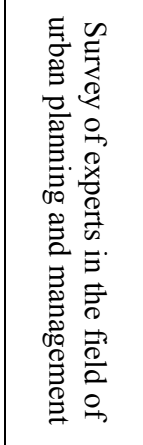 & 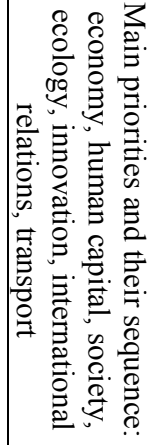 & 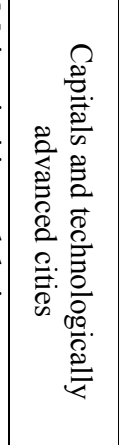 & 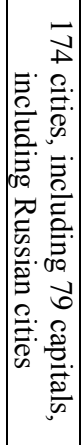 & 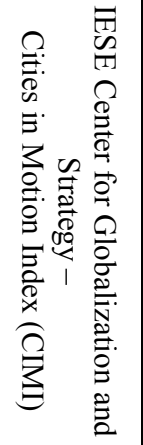 \\
\hline 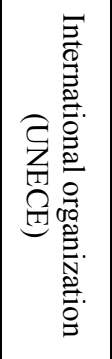 & 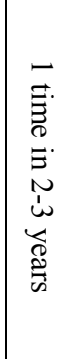 & $\frac{w}{N}$ & 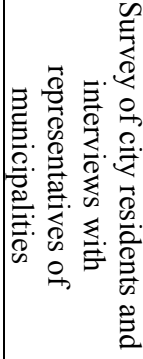 & 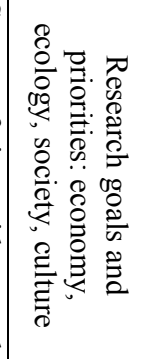 & 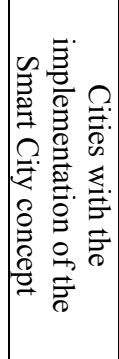 & 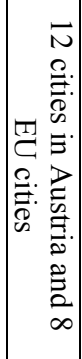 & 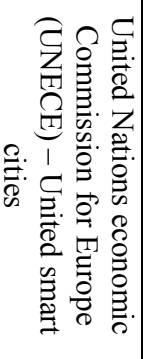 \\
\hline 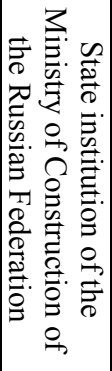 & 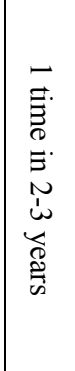 & $\begin{array}{l}\overrightarrow{0} \\
\stackrel{i}{1} \\
\stackrel{1}{0}\end{array}$ & 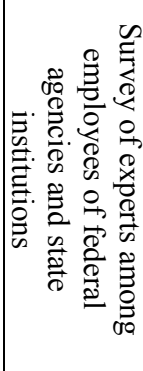 & 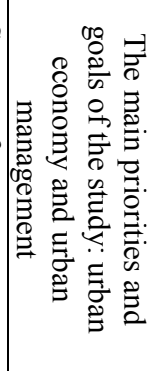 & 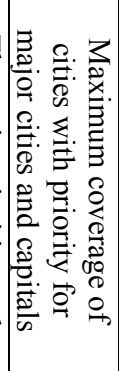 & $\begin{array}{l}\overrightarrow{0} \\
N \\
\Omega \\
\stackrel{0}{0} \\
* \\
*\end{array}$ & 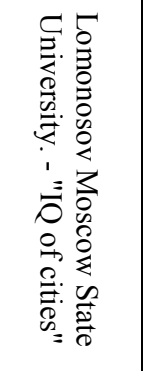 \\
\hline
\end{tabular}


- expert survey of the employees of state institutions and federal agencies ("IQ of cities»);

2) a distinctive feature of the "IQ of cities" method is the assessment of urban economy and urban management as the main priorities for applying the rating method;

3 ) the scope of the rating assessment of the UNECE and "IQ cities" is local and covers the countries of Western Europe and the cities of the Russian Federation ("IQ cities").

In general, having a number of common features, criteria and characteristics, the methods under study have one significant drawback: the lack of criteria for assessing the quality of life of the population in general and certain categories of the population in particular.

It should be noted that quality of life covers a wide range of scientific disciplines and approaches, presenting interdisciplinary concept, reflecting the efficiency of different sides of life and of human life, including "the level of satisfaction of material, spiritual and social needs, the physical, cultural and intellectual development, and the degree of security of life", which suggests the existence of a relationship between successful implementation of smart city indicators and quality of life as such [11].

In this regard, the author's definition is proposed, according to which, "smart city" is an environment that provides comfortable conditions for human life and activity within urban space based on the principles of optimal urban management and organization of urban space using innovations in the form of digital and information and telecommunications technologies that contribute to improving the quality of life and safety of people and the environment.

\section{Discussion}

The methodology of smart city metarating is based on the principles and approaches of metaanalysis, which combines the results of various scientific studies. Meta-analysis can be performed when there are multiple scientific studies focusing on the same issue, with each individual study reporting measurements that are expected to have variances and even errors of varying degrees [12]. The goal is to select scientific approaches for obtaining aggregated indicators that combine common parameters used in different rating systems for smart cities.

The core, variable, and adaptive indicators identified in the study have specific applications within each of the rating methods considered, that contributes to both the unity of priorities and the variety of available tools for evaluating smart cities. In addition, universal indicators (indicators of human capital, social security and protection, environmental indicators, economic development indicators, innovation and technology indicators) have their own variations and differences related to the difference in the goals and objectives of rating assessments, that is manifested in the degree of concretization and detail of the study of certain processes and results achieved [13]. In turn, variable indicators (indicators of international interaction, indicators of industry specifics, indicators of urban planning, and indicators of transport and mobility) not only provide an additional variety of estimated parameters, but also allow you to identify weaknesses in the ratings used for smart cities. No less important are adaptive indicators that take into account regional specifics and socioeconomic aspects (migration policy, threats of terrorism, quality of recreation, etc.) [14]. As an aggregate indicator that plays the role of an integrating parameter, it is advisable to use an indicator of the quality of life of the population. In general, the results of the study should contribute to further improvement of rating methods and successful implementation of smart city concepts.

Thus, the hypothesis that there are generally applicable criteria and indicators that represent the core, as well as variable and adaptive indicators used in the methods of smart cities rating applied by international organizations and Lomonosov Moscow State University, has been confirmed. 
A set of core indicators can be used as a basis for assessing the quality of life of individual social groups and the population as a whole and can be used as an aggregate indicator when compiling a smart city meta-rating [15]. The feasibility of this proposal is due to the fact that the rating of the quality of life of the population is based on the relationship of factors of social, economic, and environmental well-being, as well as opportunities for personal growth, technological progress, and innovation [16]. All this provides an optimal level of "psychological, emotional, physical and social health of a person, which is based on satisfaction with the perception of their place in society".

\section{Conclusion}

Based on the results of the study, the "IQ of cities" methodology was compared with the methods used by foreign experts of international organizations in the field of "smart cities" rating:

- scale and coverage: the priority method is the IESE method, the main advantage of which is the process of its application, all the capitals and major cities of the world are subjects of research: London, New York, Amsterdam, Paris, and Reykjavik;

- purposefulness of innovative development and digitalization of management processes and economic activities of cities: the priority is the "IQ of cities" methodology proposed by Lomonosov Moscow State University, focused on studying trends and difficulties associated with the digitalization of the urban environment and conditions for the introduction of digital technologies in the economic spheres of urban life, which is the main criterion (digitalization), comparing approaches to evaluating the concept of "smart city";

- number of indicators and methodology: IESE rating is a priority, since it has the widest range of used indicators ( 96 indicators);

- flexibility of the used scale: the leader is the UNECE, whose assessment involves the use of three levels of gradation of the used criteria: $0-5,0-10$ and $0-100$ points in the rating assessment;

- in terms of the sample size and the number of the studied cities, the priority is the methodology proposed by the Intelligent Community Forum, which covers up to 200 cities worldwide.

Thus, based on this study, we can conclude that the "IQ of cities" methodology, developed by the Ministry of Construction together with Lomonosov Moscow State University, is an effective technology that is not inferior to foreign models for rating urban economy and management applying innovative digital systems, which meets the requirements of the time and the needs of society. The disadvantage of this method is the lack of targeted criteria for assessing the quality of life, as well as its limited use outside the Russian Federation, and the lack of adaptation to foreign analogues.

\section{References}

1. Giourka, P., Sanders, M.W.J.L., Angelakoglou, K., Pramangioulis, D., Nikolopoulos, N., Rakopoulos, D., Tryferidis, A., Tzovaras, D. (2019). The Smart City Business Model Canvas - A Smart City Business Modeling Framework and Practical Tool. Energies, 12(24), 4798.

2. Chaturvedi, K., Matheus, A., Nguyen, S.H., Kolbe, T.H. (2019). Securing Spatial Data Infrastructures for Distributed Smart City applications and services. Future Generation Computer Systems, 101, 723-736. 
3. Attoh, K., Wells, K., Cullen, D. (2019). "We're building their data": Labor, alienation, and idiocy in the smart city. Environment and Planning D-Society \& Space, 37(6), 1007 1024.

4. Husar, M., Ondrejicka, V. (2019) Social Innovations in Smart Cities - Case of Poprad. Mobile Networks \& Applications, 24(6), 2043-2049.

5. Derickson, K., Oswin, N., Vasudevan, A. (2019). Society and Space editorial team changes. Environment and Planning D: Society and Space, 37(1), 3-5.

6. Gandy, O.H. Jr., Nemorin, S. (2018). Toward a political economy of nudge: smart city variations. Information, Communication \& Society, 22(14), 2112-2126.

7. Reddy Kummitha, R.K. (2019). Smart cities and entrepreneurship: An agenda for future research. Technological Forecasting and Social Change, 149, 119763.

8. Abu Bakar, N., Selamat, A., Krejcar, O. (2019) Improving Agent Quality in Dynamic Smart Cities by Implementing an Agent Quality Management Framework. Applied Sciences - Basel, 9(23), 5111.

9. Lau, B. P. L., Marakkalage, S. H., Zhou, Y. R., Ul Hassan, N., Yuen, C., Zhang, M., Tan, U. X. (2019). A survey of data fusion in smart city applications. Information Fusion, 52, 357-374.

10. Sáncheza A.J., Rodríguezb, S. Prietab, F. González, A. (2019). Adaptive interface ecosystems in smart cities control systems. Future Generation Computer Systems - The international journal of escience, 101, 605-620.

11. Pribyl, O., Pribyl, P., Lom, M., Svitek, M. (2019). Modeling of Smart Cities Based on ITS Architecture. IEEE Intelligent Transportation Systems Magazine, 11(4), 28-36.

12. Zanella, A., Bui, N., Castellani, A., Vangelista, L., Zorzi, M. (2014). Internet of things for smart cities. IEEE Internet of Things Journal, 1(1), 22-32.

13. Lauzi M. (2019). Smart City: Technische Fundamente und erfolgreiche Anwendungen. Carl Hanser Verlag GmbH \& Co.

14. Townsend E. (2019). Smart cities: big data, civilian hackers and the search for a new utopia. Moscow: Publishing house of the Institute of Gaidar.

15. Karaca Y., Bayrak Ş., Yetkin E.F. (2017) The Classification of Turkish Economic Growth by Artificial Neural Network Algorithms. In Gervasi O. et al. (Eds.), Proceedings of Computational Science and Its Applications - ICCSA 2017 (pp. 115126). Cham: Springer.

16. Bawa, M., Caganova D., Szilva, I., Spirkova, D. (2016). Importance of Internet of Things and Big Data in Building Smart City and What Would Be Its Challenges. In A. LeonGarcia et al. (Eds.), International Summit, Smart City 360 (pp. 605-616). ICST Institute for Computer Sciences, Social Informatics and Telecommunications Engineering. Cham: Springer. 